\title{
Radio-pathologic review of a rare benign nasal cavity tumor: A case report of angioleiomyoma of the nasomaxillary junction
}

\author{
A Nada, F Salik, A Humera \\ Radiology Department, University of Missouri Healthcare, Columbia, MO
}

\section{Purpose:}

Angioleiomyoma of the nasal cavity is a rare benign tumor of the nasal cavity. We present a case of a pathologically angioleiomyoma of the nasomaxillary junction review the characteristic imaging findings of the angioleiomyoma of nasal cavity and correlate with clinicopathological data.

\section{Case presentation:}

69-year-old male presented for evaluation of a 10year history of worsening left sided fullness of the cheek and left nares. He first noticed intermittent pain in his left jaw and along his teeth; thought to be related to sinusitis. The patient's symptoms didn't improve on treatment. The physical examination revealed a large submucosal mass emanating from the left maxilla and obstructing left anterior nasal cavity. Flexible endoscopic laryngopharyngoscopy was done and confirmed that the large submucosal mass arising from lower left lateral wall of the nose. The patient underwent local excision of this mass. CT sinus and MRI of the maxillofacial region were performed and showed a large lobulated avidly enhancing mass centered on the left naso-maxillary junction. The mass involves the anterior portions of middle and inferior turbinates. This mass extends into the anterior maxillary alveolus, hard palate and root of central/lateral maxillary incisor teeth. It has a mild mass effect on the bony nasal septum without infiltration. Mild cortical irregularities and bone demineralization of adjacent medial wall of the laeft maxilla noted. No evidene of gross bone destruction, posterior nasal/nasopharyngeal, intramaxillary or intra-oral extension.

\section{Discussion and conclusion:}

Angioleiomyoma of the nasal cavity is a rare benign tumor. This tumor has significant T2 hyperintensity and avid post-contrast enhancement. These may resemble venous malformation. They lack the significant signal void characteristic of arterio-venous malformation and aggressive behavior of malignant nasal cavity neoplasms.
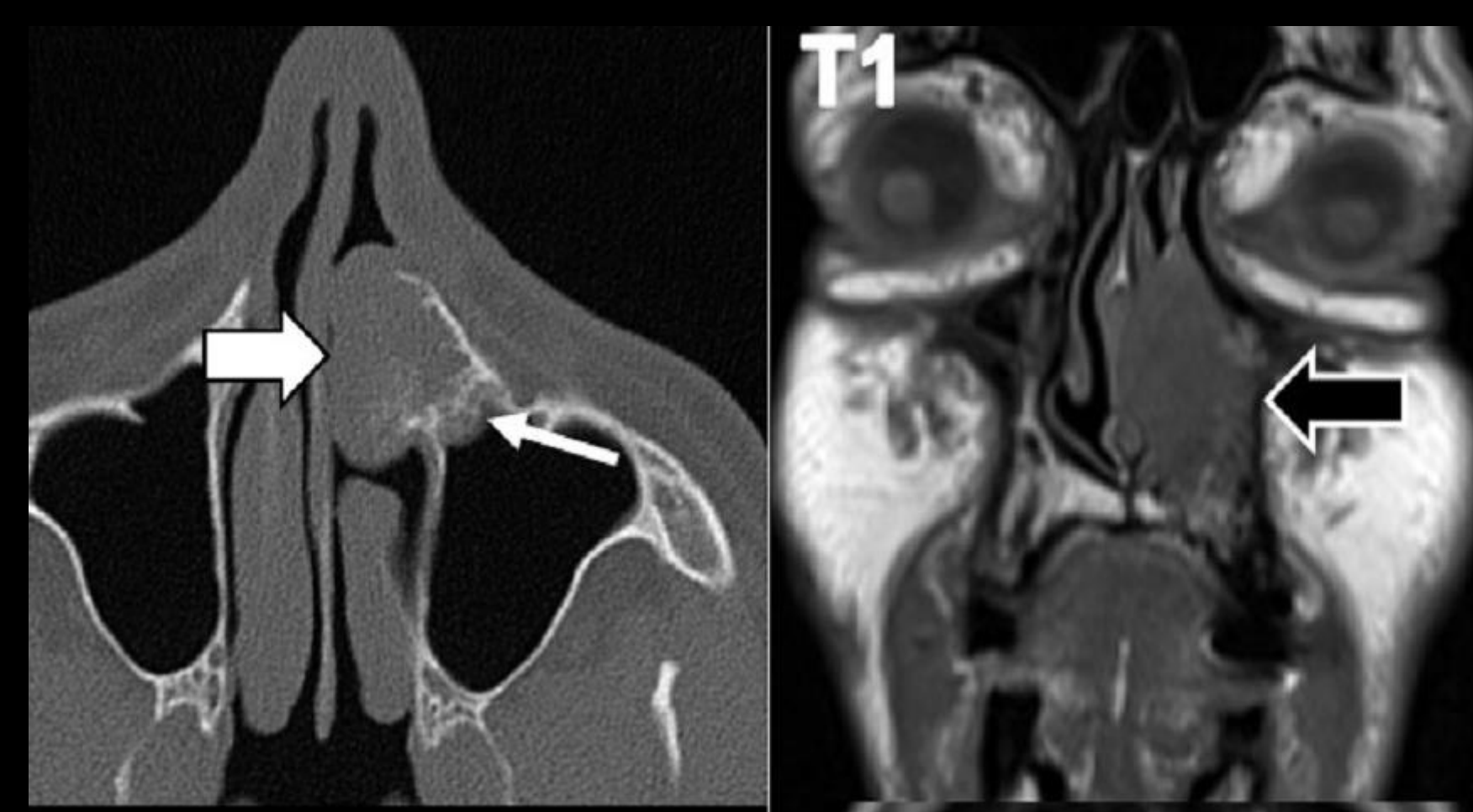

\section{STIR}

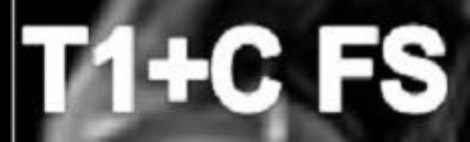

\section{References:}

- Arruda MM, Monteiro DY, Fernandes AM, et al. Angioleiomyoma of the nasal cavity. Int Arch Otorhinolaryngol. 2014;18(4):409-411. doi:10.1055/s0033-1364173

- Burkart S, Schoenenberger U. A Rare Differential Diagnosis of a Nasal Tumor: Case Report and Literature Review. Case Rep Otolaryngol 2015;2015:318620. doi:10.1155/2015/318620

- Rodriguez DP, Orscheln ES, and Koch BL. Masses of the Nose, Nasal Cavity, and Nasopharynx in Children. RadioGraphics 2017; 37:1704-1730 - Varadarajan VV, and Justice JM. Angioleiomyoma of nasal septum: Case report and literature review. Otolaryngology Case Reports; 2016 1(1): 1-4 